Results: Out of a total of a 124 responders, 82 were doctors with various degrees in training (fellow trainees, specialists in Rheumatology, Head of Department), 37 medical assistants, 3 nurses, a physical therapist, one clinical psychologist. Mean age in the group was 38.3 years old with a strikingly female dominance $(87.6 \%)$. Within the responders, the financial factor represented by monthly salary or bonuses had no or little impact on work motivation during the pandemic since more than $70 \%$ answered with "not al all / to a small extent / moderately". Regarding motivation through working hours, $26.7 \%$ responded either "not at all" or "to a small extent", $32.4 \%$ were moderately motivated while only $12.4 \%$ were more enthusiastic. More than half $(53.4 \%)$ of the staff stated that motivation was not entirely affected by working conditions in the hospital. Answers were relatively equally divided referring to motivation by safety at their workplace (almost $20 \%$ for each statement), and $40.9 \%$ suffered some extent of demotivation due to risk of contamination while caring for COVID19 positive patients. $42 \%$ of the staff was only moderately motivated by hospital's measure to limit the spread of COVID throughout the personnel. Almost $75 \%$ of the healthcare workers were not motivated by news media. Around $54 \%$ said that personal motivation was not influenced by a larger work volume and $43 \%$ were very much motivated by work relationships with colleagues. $41 \%$ of the staff is only moderately satisfied with their work during the COVID outbreak while $18 \%$ are not at all satisfied. Finally, the last open-question confirmed that for some the pandemic period was a time to bring healthcare professionals together to a stronger bond. Other responders felt that chronic rheumatic patients were left aside, while caring mostly for COVID19 patients and only limited admissions for life-threatening conditions. Moreover, medical staff suggested that the lack of a more frequent testing throughout the personnel to avoid contamination was demotivating, while still living with families or relatives.

Conclusion: Motivation of the personnel is a process with great economic and social impact. This study challenged the level of healthcare staff in difficult times caused by medical crisis. Results of the enquiry showed that financial benefits had no impact on motivation. Harsher working conditions or larger volume did not negatively impact motivation of staff, but the fear of contamination was considerable. Apparently the media influence was not a motivator for medical staff during the outbreak. Medical teams should find their stamina until the end of pandemia. REFERENCES:

[1] Barati, M, Bashirian, S et al, Factors associated with preventive behaviours of COVID-19 among hospital staff in Iran in 2020: an application of the Protection Motivation Theory, Journal of Hospital Infection 2020.

[2] Barati, M, Bashirian, S et al, Factors associated with preventive behaviours of COVID-19 among hospital staff in Iran in 2020: an application of the Protection Motivation Theory, Journal of Hospital Infection 2020.

Disclosure of Interests: None declared

DOI: 10.1136/annrheumdis-2021-eular.3271

\section{AB0880-HPR FACTORS THAT INFLUENCE PREGNANCY DECISIONS IN WOMEN WITH RHEUMATIC DISEASES}

J. E. Compeán-Villegas ${ }^{1}$, D. Á. Galarza-Delgado ${ }^{1}$, C. M. Skinner Taylor ${ }^{1}$,

L. Pérez Barbosa', R. Moyeda Martinez', R. A. Rodriguez Chavez', L.

G. Espinosa Banuelos", A. Y. Lujano Negrete ${ }^{1} .{ }^{1}$ Hospital Universitario "Dr. José

Eleuterio González", Rheumatology, Monterrey, Mexico

Background: The reproductive capacity of women with rheumatic diseases (RD) could be affected by factors such as sexual dysfunction, reduced gonadal function, foetal losses, drugs, and personal choices ${ }^{\left[{ }^{1]}\right.}$. Studies have suggested that women with $\mathrm{RD}$ may underestimate their reproductive capacity ${ }^{[2]}$, which may be reflected in unplanned pregnancies and/or adverse outcomes. One study found that women with rheumatoid arthritis (RA) have longer time to pregnancy compared to those without RA, suggesting that a reduction in fertility may be involved ${ }^{[3]}$. Another study found that patients with RA have more subfertility related to medication ${ }^{[4]}$. Aspects of sexual and reproductive health are not routinely addressed, so they are areas of opportunity to improve quality in care and research.

Objectives: Identify demographic and clinical factors associated with pregnancy decision in women with RD.

Methods: A population study was carried out including women with RD who had their first obstetric event from September 2017 to November 2020. According to the onset of sexual life and the year of conception of the first pregnancy, two groups were formed, who conceived before and after 5 years elapsed. Demographic and clinical data were obtained from medical records. Categorical variables were assessed using $\chi^{2}$ test and Fisher's exact test where appropriate. Student's t-test was used to assess continuous variables. A p value of 0.05 or less was considered significative.

Results: Data were collected from 28 women, the main diagnosis was rheumatoid arthritis $(21,75 \%)$, followed by systemic lupus erythematosus $(7,25 \%), 14$ of them $(50 \%)$ were pregnant in the first 5 years after starting sex life. There were no differences in age of onset of sex life $(p=0.362)$, or other clinical characteristic, but women with pregnancies in the first lustrum had lower percentages of marriage union ( $35 \%$ vs $42 \%$ ), paid-work ( $21 \%$ vs $28 \%$ ), and use of highly effective contraception (21\% vs $28 \%)$.
Conclusion: Conclusions: No factors were identified for pregnancies in the first lustrum, but there is a tendency to occur in single women, non-employees, and users of non-highly effective contraceptives methods. Further studies with a larger population are necessary to find modifiable factors and improve outcomes.

Table 1. Clinical characteristics.

\begin{tabular}{llll}
\hline & $\begin{array}{l}\text { Obstetric event } \\
\text { before 5 years }\end{array}$ & $\begin{array}{l}\text { Obstetric event } \\
\text { after 5 years }\end{array}$ & p-value \\
\hline Total & 14 & 14 & \\
Current average age & $24.85+/-4.3$ & $29.92+/-5.7$ & 0.404 \\
Age at the first obstetric event, years & $20.92+/-2.9$ & $28.00+/-5.9$ & 0.05 \\
Age at the onset of rheumatic disease, years & $20.71+/-5.5$ & $23.42+/-4.0$ & 0.135 \\
Average age of onset of sex life, $\mathrm{n}(\%)$ & $18.64+/-2.9$ & $18.07+/-2.5$ & 0.362 \\
Alcoholism consumption, $\mathrm{n}(\%)$ & $3(21.42)$ & $4(28.57)$ & 0.663 \\
Tobacco use, $\mathrm{n}(\%)$ & $3(21.42)$ & $3(21.42)$ & \\
Diabetes mellitus, $\mathrm{n}(\%)$ & $0(0)$ & $1(7.14)$ & 0.309 \\
Hypertension, $\mathrm{n}(\%)$ & $1(7.14)$ & $0(0)$ & 0.309 \\
Depression, $\mathrm{n}(\%)$ & $3(21.42)$ & $1(7.14)$ & 0.280 \\
Anxiety, $\mathrm{n}(\%)$ & $2(14.28)$ & $1(7.14)$ & 0.541 \\
Pre-pregnancy medication & & & \\
Methotrexate, $\mathrm{n}(\%)$ & $3(21.42)$ & $5(35.71)$ & 0.403 \\
Leflunomide, $\mathrm{n}(\%)$ & $1(7.14)$ & $2(14.28)$ & 0.541 \\
Sulfasalazine, $\mathrm{n}(\%)$ & $3(21.42)$ & $2(14.28)$ & 0.622 \\
Hydroxichloroquine, $\mathrm{n}(\%)$ & $6(42.85)$ & $4(28.57)$ & 0.430 \\
Azathioprine, $\mathrm{n}(\%)$ & $1(7.14)$ & $0(0)$ & 0.309 \\
Cyclophosphamide, $\mathrm{n}(\%)$ & $2(14.28)$ & $0(0)$ & 0.142 \\
Glucocorticoids, $\mathrm{n}(\%)$ & $5(35.71)$ & $5(35.71)$ & \\
\hline
\end{tabular}

NA: Not applicable.

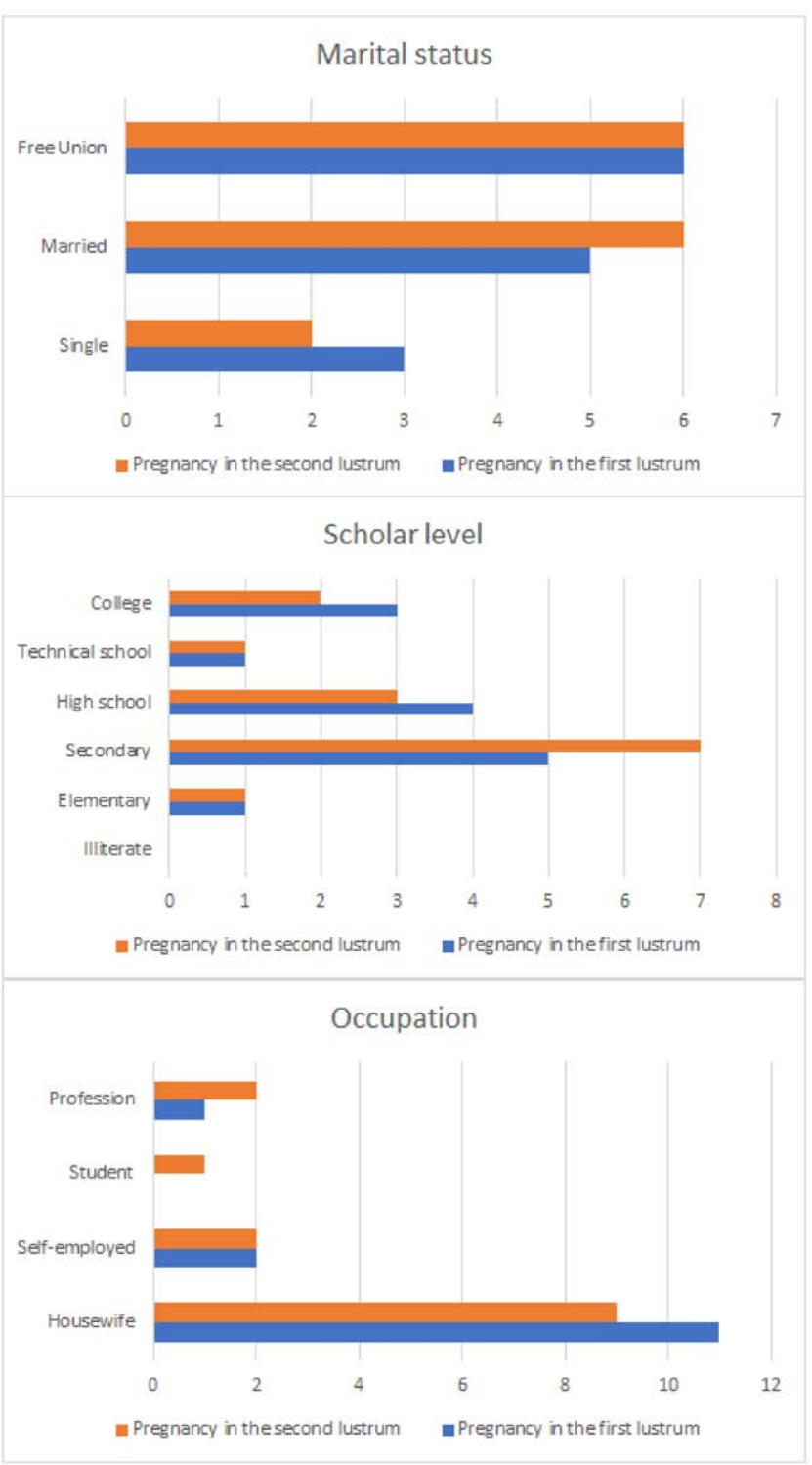

Image 1. Demographic characteristics 


\section{REFERENCES:}

[1] Østensen, M., 2017. Sexual and reproductive health in rheumatic disease. Nature Reviews Rheumatology, 13(8), pp.485-493.

[2] Birru Talabi, M., Clowse, M., Blalock, S., Switzer, G., Yu, L., Chodoff, A. and Borrero, S., 2019. Development of ReproKnow, a reproductive knowledge assessment for women with rheumatic diseases. BMC Rheumatology, 3(1).

[3] Jawaheer, D., Zhu, J., Nohr, E. and Olsen, J., 2011. Time to pregnancy among women with rheumatoid arthritis. Arthritis \& Rheumatism, 63(6), pp.1517-1521.

[4] Brouwer, J., Fleurbaaij, R., Hazes, J., Dolhain, R. and Laven, J., 2017. Subfertility in Women With Rheumatoid Arthritis and the Outcome of Fertility Assessments. Arthritis Care \& Research, 69(8), pp.1142-1149.

Disclosure of Interests: None declared

DOI: 10.1136/annrheumdis-2021-eular.3348

\section{AB0881-HPR EVALUATION OF NURSING CARE PLANS FOR RHEUMATOID ARTHRITIS PATIENTS: NURSING 2.0 PROJECT}

L. Lopez Pedraza', M. Rodero², G. Candelas ${ }^{2}$, C. Lajas ${ }^{2}$, T. Mulero López ${ }^{2}$, A. M. Perez Saez ${ }^{1}$, L. León ${ }^{1}$, Z. Rosales ${ }^{2}$, B. Fernandez ${ }^{2}$, L. Abasolo, L. Rodriguez Rodriguez ${ }^{1}$ on behalf of Investigación de la Unidad de Gestión Clínica de Reumatología del Hospital Clínico San Carlos. ${ }^{1}$ Hospital Clínico San Carlos, Instituto de Investigación Sanitaria del Hospital Clínico San Carlos (IdISSC), Reumatología, Madrid, Spain; ${ }^{2}$ Hospital Clínico San Carlos, Reumatología, Madrid, Spain

Background: A better quality of care for chronic patients is only obtainable through multidisciplinary teams. In recent years, rheumatology nurses have been involved in the remote monitoring of aged Rheumatoid Arthritis (RA) patients, as their high levels of multi-morbidity and disability make routine contacts too complex for patients and caregivers. Nursing health care should be evidence-based and organized to optimize the professionals' time.

Objectives: To develop a pilot study of two Nursing Care Plans (NCP) in Rheumatology consultations for Rheumatoid arthritis patients, exploring the satisfaction, disease activity, adherence and quality of life of the patients.

Methods: This is a non-randomised interventional study. All the stablished RA patients attending our clinics were offered one of the care plans, based on clinic characteristics, functional status, social needs, social support, preferences and health literacy. They are focused on three fundamental axes: adaptation, adherence and safety of the patient. We evaluated the two NCP that were created: (1) Elderly established RA face to face/phone visit, (2) Active young established RA face to face/phone visit. The study included a first baseline visit and a second visit at six months. Outcomes were adherence to treatment: using the Morisky Green questionnaire, disease activity; through the erythrocyte sedimentation rate (ESR), patient satisfaction; using the LOPSS questionnaire and quality of life: using the EUROQOL 5D questionnaire, Visual analog scale of the attention received and Visual analog scale of the care received. Final visit were compared to baseline visit in both groups. The paired Wilcoxon or McNemar test were used.

Results: We included 48 patients, 16 from the NCP 1 and 32 from the NCP 2. All patients except one from the NCP 2 were followed-up and ended the study. The mean age of the participants was 56 years. $77.5 \%$ were women. $30.6 \%$ had an active smoking habit. $46 \%$ had universitary studies. 53.1 had an active labor situation. Regarding the main outcomes: a)Disease activity, a slight decrease in activity was observed between baseline and 6 months, but without statistically significant differences. b) Quality of life, we detected some improvement in all care plans in the EQ-index and in the Visual analog scale (VAE) but there were no statistically significant variations. c) Therapeutic adherence, we show the results in the Morinsky Green questionnaire. We obtained statistical significant decrease in the percentage of patients that forgot to take their prescribed medications after 6 months $(p=0.04)$, and we also saw an increase in the percentage of patients taking medications at established times (up to $100 \%$ in all groups). d) Patient satisfaction with NCP obtained at the end of study, we used the LOPPS questionnaire. We obtained at six months a punctuation less than 1.5 (ordinal scale that 1 is good 5 is bad). e) Satisfaction of the care received by patients over the phone assessed at the end of study, it was almost $100 \%$, being $75 \%$ of the patients scores 9 or over. f) Satisfaction with the care plans assessed at the end of study, the score given by patients was almost $90 \%$, being $75 \%$ of the patients scores 8 or over.

Conclusion: After applying the NCP in both groups, we found positive results after 6 months and mainly regarding the therapeutic adherence. The program was well evaluated by the patients in terms of satisfaction of the care provided.

REFERENCES:

[1] Garner S, Lopatina E, Rankin JA, et al. Nurse-led care for patients with rheumatoid arthritis: A systematic review of the effect on quality of care. J Rheumatol 2017; 44: 757-765.
[2] Uthman I, Almoallim H, Buckley CD, et al. Nurse-led care for the management of rheumatoid arthritis: a review of the global literature and proposed strategies for implementation in Africa and the Middle East. Rheumatology International 2020; $1: 3$

[3] Bech B, Primdahl J, Van Tubergen A, et al. 2018 update of the EULAR recommendations for the role of the nurse in the management of chronic inflammatory arthritis. Ann Rheum Dis 2020; 79: 61-68.

Disclosure of Interests: Leticia Lopez Pedraza Grant/research support from: Pfizer, María Rodero Grant/research support from: Pfizer, Gloria Candelas Grant/ research support from: Pfizer, Cristina Lajas Grant/research support from: Pfizer, Teresa Mulero López Grant/research support from: Pfizer, Ana María Perez Saez Grant/research support from: Pfizer, Leticia León Grant/research support from Pfizer, Zulema Rosales Grant/research support from: Pfizer, Benjamin Fernandez Grant/research support from: Pfizer, Lydia Abasolo Grant/research support from: Pfizer, Luis Rodriguez Rodriguez Grant/research support from: Pfizer DOI: 10.1136/annrheumdis-2021-eular.3538

\section{AB0882-HPR ANCA-ASSOCIATED VASCULITIS: A CLINICAL PRACTICE ASSESSMENT}

S. Mendly ${ }^{1}$, G. Boutsalis ${ }^{2} .{ }^{1}$ Medscape Education Global, Medscape Education Global, London, United Kingdom; ${ }^{2}$ Medscape Education Global, Medscape Education Global, New York, United States of America

Background: AAV (ANCA-associated vasculitis) is a group of progressive, rare, severe autoimmune diseases ${ }^{1,2}$. AAV can affect blood vessels in different parts of the body resulting in damage to vital organs such as the lungs, kidneys, nervous system, gastrointestinal system, skin, eyes, and heart. ${ }^{2}$ There are currently no approved therapies for remission-induction in patients with AAV. The current treatment armamentarium for $\mathrm{AAV}$ is comprised of various immunosuppressive therapies in combination with steroid treatment. Understanding clinical practice gaps in the management of AAV, can inform development of tools to improve physician practices.

Objectives: This medical education activity aims to assess physicians' knowledge on the various manifestations of antineutrophil cytoplasmic antibody-associated vasculitis (AAV), current guideline-recommended treatment strategies for remission induction in patients with $\mathrm{AAV}$, as well as recent clinical trial data for combination therapies used for remission induction.

Methods: A 24-question survey consisting of multiple-choice knowledge and case-based questions was made available to nephrologists and rheumatologists without monetary compensation or charge. The questions were designed to evaluate knowledge regarding the various manifestations of $A A V$ and the results from clinical trials that have compared the efficacy of combination therapies used for remission induction in patients with AAV. As well as application of guideline-recommended therapies and clinical trial data for remission induction in patients with AAV within clinical practice. The survey launched online on a website dedicated to continuous professional development. (www.medscape.org/viewarticle/920320) on July 15, 2020. Data were collected until October 1, 2020

Results: 363 nephrologists and 190 rheumatologists completed the survey. Physicians demonstrated gaps in the following areas:

\begin{tabular}{|c|c|c|}
\hline Topic & $\begin{array}{l}\text { Incorrect Resp } \\
\text { Knowledge an } \\
\text { Decision-Maki }\end{array}$ & $\begin{array}{l}\text { ponses to } \\
\text { id Clinical } \\
\text { ing Questions (\%) }\end{array}$ \\
\hline & Nephrologists & Rheumatologists \\
\hline Systemic diseases associated with AAV & $59 \%$ & $45 \%$ \\
\hline How to confirm diagnosis of AAV & $42 \%$ & $25 \%$ \\
\hline $\begin{array}{l}\text { Therapy selection to induce remission that would be } \\
\text { consistent with guidelines recommendations }\end{array}$ & $71 \%$ & $51 \%$ \\
\hline $\begin{array}{l}\text { Guideline-recommended therapy for patients that do not } \\
\text { respond to the induction regimen }\end{array}$ & $32 \%$ & $34 \%$ \\
\hline Definition of refractory disease & $95 \%$ & $94 \%$ \\
\hline $\begin{array}{l}\text { Most effective maintenance strategy for a patient once } \\
\text { remission is achieved }\end{array}$ & $80 \%$ & $64 \%$ \\
\hline $\begin{array}{l}\text { Where would an emerging therapy such as a C5a recep- } \\
\text { tor inhibitor fit into the therapeutic armamentarium of } \\
\text { AAV? }\end{array}$ & $62 \%$ & $47 \%$ \\
\hline $\begin{array}{l}\text { What are the guideline-recommended therapies to } \\
\text { reduce remission in patients without organ-threatening } \\
\text { disease? }\end{array}$ & $71 \%$ & $51 \%$ \\
\hline $\begin{array}{l}\text { Most effective maintenance strategy for a patient once } \\
\text { remission is achieved }\end{array}$ & $80 \%$ & $64 \%$ \\
\hline $\begin{array}{l}\text { Guideline-recommendations on length of time to continue } \\
\text { maintenance therapy }\end{array}$ & $31 \%$ & $35 \%$ \\
\hline
\end{tabular}

Conclusion: This educational research on assessment of physicians' (nephrologists and rheumatologists) clinical practices yielded important insights into clinical gaps related to understanding of the disease pathophysiology and 